\title{
Bolonia, una oportunidad para el derecho deportivo
}

\section{Bolonia, a opportunity to Sport Law}

\section{Francisco de la Torre Olid ${ }^{1}$, Francisco Martínez Rivas ${ }^{2}$}

1 Catedrático de Derecho Civil. Universidad Católica San Antonio. Murcia. España

2 Profesor Adjunto de Derecho Internacional. Universidad Católica San Antonio. Murcia. España

\author{
CORRESPONDENCIA:
}

Francisco de la Torre Olid / Francisco Martínez Rivas Universidad Católica San Antonio de Murcia (UCAM) Departamento de Ciencias Sociales, Jurídicas y de la Empresa Campus de Los Jerónimos, s/n 30107 Guadalupe (Murcia)

\section{Resumen}

El nuevo panorama universitario, adaptado al Plan de Bolonia, ha exigido una revisión de estudios de larga tradición como son los de Derecho y este momento ha permitido implantar unos nuevos planes en los que el Derecho del deporte tiene un espacio. Este estudio razona sobre la importancia de esta materia por la consideración de su contenido interdisciplinar, que ejercita en la visión unitaria del Ordenamiento, y por la realidad tan universal que acota, que hace necesario su conocimiento por el jurista, que es un profesional Ilamado a intervenir en la sociedad e implicarse en lo que ésta se proyecte. Se muestra una experiencia para dibujar, desde la UCAM, un itinerario procedimental y una realidad universitaria que puede inspirar otras iniciativas académicas, con el compromiso con el Derecho deportivo que familiariza con el deporte y contribuye a su fomento; además de exigir estar a resultas de la actualización de un Derecho que, al ser novedoso en su relevancia jurídica, se ha de seguir completando y consolidando.

Palabras clave: Bolonia, Derecho-Deporte, Valores, interdisciplinariedad.

\begin{abstract}
Adapting to the Bologna plan, the University panorama has required a review of subjects of long history such as Law, what is also a chance to introduce new programs to the subject such as Sports Law. Lawyers need to know Sports Law, since they are professionals who intervene in Society and in all its facets. Due to the importance of this subject, determined by its multidisciplinary content, provides a global vision of the legal system. Consequently, it is a chance to redraw procedures so that others in the University may be inspired to modernize other subjects with commitment to a Sports Law which brings it closer to sports and contributes to its development, besides, it requires to be constantly updated and consolidated itself.
\end{abstract}

Key words: Bologna, Sports-Law, Values, multidisciplinary. 


\section{EI EEES como escenario en el que tratar una realidad universal}

Bolonia (el Plan que ha determinado las reglas de conformación y adaptación al Espacio Europeo de Educación Superior -EEES-) puede considerarse una oportunidad para el Derecho Deportivo, para su inclusión como materia de estudio en los nuevos Grados y, en particular, en la programación del Grado de Derecho; además de su posible y ulterior inclusión en programas de doctorado y en estudios de especialización.

Se parte de un nuevo marco normativo que exige la revisión de los estudios universitarios y la formación de los nuevos títulos, cuya programación sigue las determinaciones y requisitos establecidos en el $R D$ 1393/2007, de 29 de octubre ${ }^{1}$. Por tanto, nos encontramos en el momento ideal para atender la oportunidad de la que se dice disponer para que los estudios de Grado y de Postgrado dediquen un espacio a este nuevo Derecho o, al menos, para que lo contemplen como opción próxima, dada la flexibilidad con la que se programa a través de las herramientas de planificación sujetas a revisión periódica para el control de calidad y actualización o ajuste a las exigencias de la realidad a la que se sirve. Proponiéndose contemplar esta inclusión del Derecho del deporte en los planes de estudio del Grado de Derecho, sobre todo porque no se pretende sólo abordar una reforma en lo puramente formal (un nuevo calendario académico, una nueva traducción en créditos, etc.) sino que se invita a reflexionar sobre el contenido idóneo y nuevo, en su caso, de los títulos.

Pues bien, así se ha entendido en la Universidad Católica San Antonio de Murcia, donde se ha incluido ya esta materia de Derecho del Deporte en los estudios de Derecho, concretamente ofertándola como asignatura optativa ${ }^{2}$. Esta actuación es legítima por la autonomía universitaria de la que se goza en la Institución y es válida desde la homologación que la verificación del Título por el Ministerio de Educación ha merecido, previo informe favorable de la $\mathrm{ANECA}^{3}$; pero, sobre todo, se defiende y motiva la conveniencia de esta iniciativa académica con el desarrollo de este trabajo.

Desde luego, son variadas, y todas ellas importantes, las razones que han sugerido y motivado esta in-

\footnotetext{
1 Real Decreto 1393/2007, de 29 de octubre, por el que se establece la ordenación de las enseñanzas universitarias oficiales, Boletín Oficial del Estado, 260, de 30 de octubre de 2007, pp. 44037-44048, modificado parcialmente por el RD 861/2010 de 2 de julio, Boletín Oficial del Estado, 161, de 4 de julio de 2010, pp. 58454-58468.

2 Asignatura Derecho del Deporte, del grupo 2, del séptimo cuatrimestre, con 6 créditos ECTS

3 Resolución del Ministerio de Educación de 30 de julio de 2009.
}

clusión del Derecho deportivo en los planes de estudio universitarios.

De partida, se asume en toda institución universitaria el compromiso de responder, como servicio público $^{4}$, a la demanda social de formación en materias que precisen de estudio y capacitación para el mercado laboral, para dirigir profesionalmente a una población invitada (o "recetada" y compelida por exigencia médica $^{5}$ ) al deporte y que por la afluencia precisa de una alta gestión y organización ${ }^{6}$.

La Universidad es también la sede legitimada para el tratamiento en profundidad de cualquier ciencia. Y es la idea de servicio público la que debe marcar la docencia y la investigación de estas sedes pensando en la empleabilidad (según late en toda la reforma que se ha articulado con el citado Real Decreto de ordenación de los Títulos Universitarios); y evitar que argumentos tan profundos como la autonomía universitaria sirvan para, equivocadamente, justificar que la formación y la iniciativa científica de la universidad se separen de la sociedad y, por ende, del mercado.

Más en particular, nuestra Universidad hace una apuesta por el deporte y es ese espíritu (en clave de fundamentos), y las sinergias que un cuadro de títulos permite aprovechar (en clave de organización y viabilidad de organización), lo que explica su particular iniciativa.

No se trata la materia deportiva sólo en la Titulación de Derecho, también se aborda y se oferta desde estos estudios a la Comunidad Universitaria y, en particular, a la Titulación de Ciencias de la Actividad Física y del Deporte; como también en varios estudios de Postgrado dedicados a la actividad física y al deporte, como el Máster de Traumatología del Deporte, el Máster de Danza y Artes del Movimiento y el Máster de Gestión de Entidades Deportivas. Además, en el mapa de títulos se reconocen otros que tienen una vinculación necesaria como el Grado de Fisioterapia e incluso en la oferta académica extraordinaria son otras muchas la

\footnotetext{
4 Servicio Público que es definidor de la institución universitaria, como dispone el art. $1^{\circ}$ de la Ley Orgánica 6/2001, de 21 de diciembre, de Universidades, Boletín Oficial del Estado, 307, de 24 de diciembre de 2001, pp. 49400-49425.

5 Desde enero de 2011 se ha protocolizado la posibilidad de que los facultativos receten a los enfermos la práctica deportiva, para lo que se ha articulado una red de tutores profesionales que conducen a esos grupos de pacientes.

6 "y un gestor de una actividad deportiva no puede desconocer el Derecho deportivo a la hora organizar-gestionar-administrar con calidad una actividad deportiva... Resulta evidente que nos movemos en un mundo donde las normas y criterios jurídicos tienen especial relevancia". Sánchez Rodríguez, F. y Punzón Moraleda, J. (2009) La inclusión del "derecho deportivo" en los nuevos títulos de grado de la física y del deporte. Revista Aranzadi de Derecho del Deporte y Entretenimiento, 25, 28.
} 
iniciativas como cursos de libre configuración ${ }^{7}$ y congresos $^{8}$ en donde tiene cabida el Derecho del deporte.

Sin embargo, podría objetarse que, en unos estudios generalistas como efectivamente son los de Grado, no tendría que tener cabida un Derecho especial. Frente a esa consideración negativa se tiene que sobreponer el argumento de la conveniente apuesta por un Derecho ordenador de una realidad universal que, además, debe consolidarse e incluso aumentar en su frecuencia y posibilidades de manifestación.

Constituye el hecho deportivo una realidad emergente pero que está llamada a propagarse por los valores que aporta a la mejora y realización de la persona y de la sociedad. Por tanto, en esa complejidad derivada de tan vasta actividad, se tiene que desarrollar un conjunto normativo ordenador de la misma por lo que el Derecho deportivo se desarrolle como especial y novedoso. El cual va a tener que dar respuestas jurídicas particulares y sin mayor tradición que la que los principios y fundamentos del sistema jurídico exigen e informan para preservar una unidad y coherencia del Ordenamiento. De igual modo se puede afirmar que si ese hecho deportivo es tan relevante que caracteriza a la sociedad, en gran parte de su configuración y de su actividad; y si presenta tantas ventajas, sobre todo como escuela de valores ${ }^{9}$, su tratamiento y estudio se hace necesario para abarcar una universalidad y, al estar impregnado de la ejemplaridad que la actividad objeto de regulación presenta, su referente también sirve al estudio generalista.

Un Derecho generalista porque afecta al ciudadano en su consideración individual, abstracción hecha de toda proyección patrimonial; y en su proyección natural social, que ordena una actividad que normalmente desarrolla toda persona, por sí sola o en relación con terceros; y que contiene aspectos jurídicos relevantes, cuando menos por implicar su necesario ejercicio en

7 Se destaca una iniciativa interesante que tiene un carácter mixto jurídico deportivo que como cursos de verano ha alcanzado un cierta tradición al estar ya en su cuarta edición, consistente en unas enseñanzas de iniciación a la escalada y, en el mismo enclave de montaña, se imparte a los alumnos una clase teórica sobre los fundamentos de la responsabilidad y los criterios jurisprudenciales en los accidentes deportivos (julio de 2008, 2009, 2010. El Valle Perdido Parque Natural, Murcia).

8 Congreso Internacional de CAFD, más recientemente, en el año 2010 , el I Congreso Internacional de Atletismo; y ya en el año 2011 ha programado las XXI Jornadas Nacionales de Traumatología del Deporte.

9 Así y respecto al principio de igualdad se tiene aprobado por el Consejo de Ministros el Plan Estratégico de Igualdad de Oportunidades para el período 2008-2011, de conformidad con lo establecido en el artículo 17 de la Ley Orgánica 3/2007, de 22 de marzo, para la lgualdad efectiva de Hombres y Mujeres (Boletín Oficial del Estado, 71, de 23 de marzo de 2007 pp. 12611-12645), marco de referencia que exige una mayor presencia femenina también en el deporte. Según se explica en el trabajo de Castro Conte, M. (2009). Desarrollo legal y situación de la mujer en el deporte, Revista Aranzadi de Derecho del Deporte y Entretenimiento, 26, 95. su desarrollo personal ${ }^{10} \mathrm{y}$, cuando más, por cuanto la asunción de riesgos típicos derivados de la actividad se enfrenta a una posibilidad de quiebra de la integridad física que es bien jurídico superior (cfr. Art. $15 \mathrm{CE}$ ).

El hecho deportivo debe preservarse y favorecerse, por lo que el estudio de su tratamiento en clave jurídica, que es el objeto de esta materia, sirve para familiarizarse con aquél y así fomentarlo y despertar la vocación por la realidad material misma del deporte. En suma, se puede concluir que estudiar, jurídicamente, en este caso el deporte, es despertar y propagar su interés, fomentar su ejercicio y formar en competencias tan necesarias como el trabajo en equipo o la sensibilidad medioambiental.

Ciertamente, el tratamiento del deporte en esa clave jurídica se considera principal porque implica entender el presupuesto de mantenimiento del hecho deportivo que, más allá de sus posibles manifestaciones espontáneas y por encima de ellas, ha de garantizarse conforme a la exigencia que el texto constitucional impone a los Poderes Públicos ${ }^{11}$. Por tanto y simplificando, se podría afirmar que para que exista el deporte se ha de sujetar su realización al tratamiento jurídico. La manifestación espontánea de esta disciplina es válida, pero al ser una realidad cuya práctica genera riesgos precisa de regulación jurídica; máxime cuando a través de ésta se fomente, regule y, por ende, se garantice el deporte ${ }^{12}$.

Así, se puede afirmar que el Derecho es para el deporte garantía de realización y de desarrollo, como también es fundamental contemplar el Derecho como regulador del fenómeno deportivo porque, más allá de la clave jurídica y con ella, articula un tratamiento

10 Ya lo decía en su artículo $1^{\circ}$ de la Ley 13/1980 del Deporte de 1980, anterior a la actual de 1990, "... de la educación física y del deporte como factores imprescindibles en la formación y en el desarrollo integral de la persona". Ley 13/1980, de 31 de marzo, General de la Cultura Física y del Deporte, Boletín Oficial del Estado, 7635, 12 de abril 1980, pp. 79087913.

11 Literalmente el art. 43.3 CE dispone que "Los poderes públicos fomentarán la educación sanitaria, la educación física y el deporte. Asimismo facilitarán la adecuada utilización del ocio".

12 "Asimismo facilitarán la adecuada utilización del ocio" En este sentido de sujeción del hecho deportivo a la regulación jurídica se manifiesta la Sentencia 81/2009 del Tribunal Constitucional, de 23 de marzo de 2009, que expresa la necesidad de un mayor control de la actividad deportiva, especialmente en lo que se refiere a la colegiación obligatoria de profesores de Educación física. El Tribunal considera que es necesaria la colegiación para dicha profesión... permite evitar las repercusiones negativas que puede tener un ejercicio no adecuado de las diversas actividades físicas y deportivas, especialmente en aquellos deportes cuyo ejercicio conlleva un riesgo, sin que tampoco pueda desconocerse la importancia y valoración cada vez mayor de estas actividades, a las que los poderes públicos responden con el establecimiento de nuevas exigencias de cualificación para los profesionales dedicados a las mismas y, de modo especial, para quienes tienen como función la de docentes de esta materia en los centros de enseñanza. 
más publicista o privatista, social o comercial, que conformará el deporte como una manifestación cultural, como un negocio, etc. ${ }^{13}$

También se razona la idea del tratamiento en clave jurídica como principal en cuanto se eleva a concepto mismo de la actividad física su régimen ordenador, así, se habla de disciplina deportiva ${ }^{14}$. Y es la observancia de su régimen lo que le asegura un análisis separado, incluso en el supuesto de un accidente o acontecimiento que en otro entorno se sometería a un debate o contienda judicial. Punto éste que nos permite hablar de la autonomía del ámbito deportivo ${ }^{15}$.

Abundar en la conveniente inclusión de esta materia en la planificación de los estudios de grado de Derecho pasa por analizar las competencias que el alumno debe adquirir para proyectarse como jurista: la interpretación de la realidad en clave jurídica y el tratamiento integral de una materia que se caracteriza por una interdisciplinariedad, competencias ambas que permiten al alumno tener una visión unitaria del Ordenamiento.

Efectivamente el Derecho deportivo integra normativa civil, penal, laboral, administrativa, mercantil...; por lo que asomarse al mismo implica mantener la referencia de esa unidad del Ordenamiento y ejercitarse en la concordancia e integración de normas para solucionar problemas prácticos con implicaciones en distintas ramas o sectores del Derecho.

También viene a demostrar su tratamiento la respuesta ágil del Derecho para ordenar realidades nuevas o que lo son en su dimensión y ordenación jurídica. Consideración práctica y razonamiento crítico que se exige en el alumno que, como jurista, ha de saber reconocer el Derecho como herramienta útil para una sociedad cambiante ${ }^{16}$.

13 No son baladíes los recursos económicos que transitan alrededor de las actividades deportivas, en lo que se refiere a derechos de imagen por ejemplo destacan las consideraciones de lan S. Blackshaw y Robert C. R. Siekmann (2005). Sports Image Rights in Europe. T.M.C Asser Press La Haya.

14 Por ello el deporte es definido en el Diccionario de la Real Academia Española de la Lengua como "actividad física, ejercida como juego o competición, cuya práctica supone entrenamiento y sujeción a normas"

15 "La Carta Olímpica de 3 de septiembre de 1997, que es el código por el que se rige el Movimiento Olímpico en el que se integran las Federaciones Internacionales de los deportes más ampliamente practicados, los Comités Olímpicos Nacionales, las asociaciones nacionales, los clubes y las personas que forman parte de ellos y muy especialmente los atletas, bajo la suprema autoridad del Comité Olímpico Internacional (COI), proclama con énfasis como uno de sus principios fundamentales que "la organización y la gestión del deporte deben ser controladas por los organismos deportivos independientes reconocidos como tales". Así se recoge en el punto "El Ordenamiento Deportivo y su pretensión de autosuficiencia", en el artículo La Justicia Deportiva Internacional: El Tribunal Arbitral del Deporte, de Fernández Rodríguez, T. R. (2009). Revista Aranzadi de Derecho del Deporte y Entretenimiento, 27, 19

16 En este sentido destaca la función reguladora de actitudes y comportamientos que tienen las reglas jurídicas que prevén y corrigen las pato-
La interdisciplinariedad no excluye situar y reconocer la naturaleza fundamentalmente ius privatista y civilista del Derecho deportivo. En tanto en cuanto, este sector del Ordenamiento, como tronco común y derecho general, sirve para situar el régimen ordenador y abordar la disciplina del deporte con un papel supletorio en todo lo que no se reconozca como materia reservada al orden público, o bien como contenido propio de la norma imperativa en tanto el deporte es una expresión de libertad de la persona y una realidad de mercado. Libertad personal y de mercado que constitucionalmente se proclaman y limitan cualquier afán intervencionista (cfr. Arts. 17 y $38 \mathrm{CE}$ ), convirtiéndose en referentes precisos para entender las soluciones jurídicas más propias del deporte que permiten frenar excesos de invasión de la actividad ${ }^{17} \mathrm{y}$ dan viabilidad a una autonomía de este Derecho ${ }^{18}$ (entre otros argumentos: para salir con agilidad al ámbito internacional con una ordenación ágil y no sujeta a los criterios nacionales y para evitar la judicialización del deporte).

El conocimiento por el jurista del Derecho deportivo, desde la formación básica y generalista, tiene la lógica rentabilidad y manifestación en el fomento de la investigación y en el aumento de la empleabilidad, puesto que se precisa incorporar profesionales a un mercado laboral que demanda una creciente atención a los problemas deportivos. De igual modo, efectivamente, la investigación se garantiza y razona desde la formación generalista y la vocación oportunamente despertada.

A partir del mandato constitucional de promoción por parte del Estado del Deporte, es sencillo apreciar la relevancia jurídica del Deporte; justificándose una intervención pública por la presencia del interés ge-

\footnotetext{
logías que el deporte, como actividad intensa, muestra. Así, la normativa reguladora de la violencia en el deporte, Ley 19/2007, de 11 de julio, contra la violencia, el racismo y la xenofobia en el deporte (Boletín Oficial del Estado, 166, 12 de julio de 2007, pp. 29946-29964) exige el tratamiento especial frente a la general Ley 10/1990, de 15 de octubre del Deporte (Boletín Oficial del Estado, 249, de 17 de octubre de 1990, pp. 30397-30411). A propósito de esta necesaria especialización la Sentencia 81/2009 del Tribunal Constitucional, de 23 de marzo de 2009, donde se declara inconstitucional el derogado artículo 69.3.c

17 Precisamente la relevancia de esa libertad de la persona y el respeto a su intimidad, así como la consideración como actividad de mercado es un argumento esgrimido para oponerse a un control antidopaje excesivamente invasivo, por lo que se razona el contenido del art. 6.2 de la LO 7/2006, de 21 de noviembre, de protección de la salud y de lucha contra el dopaje en el deporte (Boletín Oficial del Estado, 279, 22 de noviembre de 2006, pp. 40859-40879) que exime de responsabilidad al deportista que no se somete a un control antidopaje en la franja horaria del descanso nocturno. Molina Navarrete, C. (2009). Revista Aranzadi de Derecho del Deporte y Entretenimiento, 26, 52.
}

18 Disciplina deportiva, predominio de la teoría de asunción de riesgos.. son dos referentes que sirven para explicar esa autonomía en la gestión, desarrollo y responsabilidades en el deporte. 
neral $^{19}$, por lo que no sólo se contempla una iniciativa legislativa en materia deportiva sino también, a partir de la tarea de fomento, una titularidad pública en la gestión deportiva. Cosa distinta es que ese referente se perpetúe hasta el punto de eliminar la consideración de la persona en el deporte que exige una visión más privada o de considerar que el modelo de gestión pública en el deporte es preferente cuando la realidad social y económica evidencian la tendencia a una mercantilización, bien entendida para hacerla rentable y, en consecuencia, perdurable ${ }^{20}$. Por tanto, un fomento del deporte exigible a los Poderes Públicos no tiene por qué traducirse en la titularidad y gestión pública de la actividad deportiva, antes al contrario puede articularse en un escenario normativo con suficientes incentivos a la iniciativa privada en la empresa deportiva.

Esta postura, defensora de un necesario aumento de la iniciativa privada en la organización del deporte, responde sin duda a una línea ideológica pero también a la necesidad de limitar el gasto público o evitar que la falta de recursos públicos no debilite la actividad deportiva. Sin embargo, las Administraciones (sobre todo las autonómicas, con su afirmación decidida y rotunda en los estatutos de "segunda generación") no se resisten a intentar asumir el liderazgo en el ámbito deportivo, en gran medida por la rentabilidad social y política de ese empeño; como también se ha de comprender que la actividad privada, en muchos extremos, tiene que ser dependiente de la homologación, colaboración o concesión con la actividad pública (por ejemplo en un desarrollo urbanístico o en un control de orden público en evitación de violencia o de dopaje).

Esa previsión constitucional general (ex art. $43.3 \mathrm{CE}$ ) se ha de concretar en un Estado, como es el español, ciertamente complejo desde que se configura territorialmente en autonomías. La competencia relativa a la promoción deportiva se configura como una materia transferible a las Comunidades Autónomas en nuestra Constitución (ex art. 148.19 CE). La tarea pública en esta labor no se agota, en lo relativo al deporte, en las autonomías, ni en otras Administraciones, locales y central, ni siquiera en la actuación de los demás Poderes Públicos, legislativo y ejecutivo, desde la conside-

19 En este punto se abre el debate necesario para legitimar una presencia y protagonismo de los Poderes Públicos en el deporte, tratado con rigor y profundidad, incluso en su perspectiva histórica y visión de futuro, en el artículo de Palomar Olmeda, A. (2009). Un intento de acotar el interés general deportivo: pautas para su eventual revisión y como consecuencia del papel de las Administraciones públicas en el deporte. Revista de Derecho del Deporte y Entretenimiento, 27, 185-225.

20 En este punto es útil y más profundo el estudio sobre la necesidad de la reflexión sobre el modelo de gestión pública del deporte de Palomar Olmeda, A. (2009). La modernización de la gestión pública del deporte. Revista Aranzadi de Derecho del Deporte y Entretenimiento, 25, 93-95. ración del deporte como actividad universal que trasciende del entorno territorial autonómico y demanda una tarea de la correspondiente Administración supraautonómica. Como también, la consideración del deporte como una realidad compleja, en cuanto que su desarrollo se relaciona con otras materias que van desde la ordenación del territorio, para el desarrollo de infraestructuras; hasta la educación, para el desarrollo de la personalidad y formación de la ciudadanía se relaciona con la actividad económica si el deporte se contempla desde esa necesaria realidad del mercado; por todo lo cual la competencia, la tarea pública, de garantía y fomento, desde luego, como también de ordenación general, se presenta como propia de todos los Poderes Públicos (sin dejar de insistir en que tal presencia pública necesaria desde la normativización de la actividad no tiene que perpetuarse en la titularidad y gestión sino alcanzar su viabilidad con la presentación competitiva en el mercado -pudiendo entonces ver el deporte como una oportunidad de mercado-).

Estos referentes que informan la complejidad del deporte desde esa competencia pública plural, que ya augura una suerte de normas legales de diferente origen y rango; hasta la gran implicación del deporte con otras materias jurídicas y otras leyes (de publicidad, de educación, de planeamiento urbanístico, de seguridad vial, de medio ambiente ${ }^{21}$ ), marcan un estudio necesario de unos textos legales ${ }^{22}$ antes que otras fuentes doctrinales o jurisprudenciales.

Por otra parte, la implicación de la integridad de la persona en el desempeño del deporte o también en el evento deportivo, con el papel de deportistas o de público, sea un papel más activo o más pasivo, determina que todo su desarrollo deba estar sujeto a la alerta jurídica del posible quebranto de esa integridad. Igualmente, el normal desarrollo del deporte, sin incidencia alguna, exige su consideración de actividad

21 Con razón se ha afirmado en párrafos anteriores de este trabajo que la ordenación jurídica del deporte es garantía de su viabilidad en cuanto se tiene que desarrollar, en gran medida, en un entorno natural con el que se mezcla pero que, en otras ocasiones, puede entrar en conflicto ya que son muchas las experiencias deportivas que se han desarrollado gracias a un entorno natural, como también es cierto que el deporte se sigue desarrollando sin esa dependencia del medio natural o, incluso, contra el medio natural. Variables todas ellas apuntadas en el epígrafe relativo a "Las agresiones medioambientales de la práctica deportiva", del trabajo La realización de actividades deportivas y la protección jurídica del medio natural. Monrov Antón, A.J. (2009). Revista Aranzadi de Derecho del Deporte y Entretenimiento, 25, 147-148.

22 Así y como expresión de desarrollo desde un marco constitucional ampliamente reconocido se comparan y entienden en su particular ámbito la Ley del Deporte nacional (Ley 10/1990, de 15 de octubre del Deporte, Boletín Oficial del Estado, 249, de 17 de octubre de 1990, pp. 3039730411) y la Ley del Deporte de la Región de Murcia (Ley 2/2000, de 12 de julio, Boletín Oficial de la Región de Murcia, de 29 de julio de 2009, 175, pp. 8967-8991). 
jurídicamente relevante en tanto el sujeto sumergido en la misma está, al tiempo, en pleno desarrollo de su personalidad. Tal realidad no es inocua sino tan relevante como la preferencia constitucional a tal desenvolvimiento propio de la dignidad explica.

La especialización, después del Grado, será lógica para un jurista formado en el Derecho general y será muy conveniente para profundizar en el Derecho deportivo que, ganando la autonomía antes apuntada, conforma un corpus importante con soluciones jurídicas particulares (fiscales, laborales, administrativas... ${ }^{23}$ ).

Esa especialización necesaria del jurista y la consolidación de la autonomía del derecho deportivo explican la profundización con la investigación y producción científica que se materializa en creación de cátedras, profusión de publicaciones y otros. Todo ello permite dar tratamiento y soluciones a la novedad que la realidad deportiva presenta en múltiple aspectos, por ejemplo, con la movilidad de las personas, la construcción de infraestructuras en su dimensión, en su seguridad y ubicación; la prevención de la violencia, la evitación del dopaje, el desarrollo de la publicidad, la explotación de la imagen... Porque el Derecho del deporte tiene que solucionar importantes cuestiones que presentan, de entrada, retos para lograr importantes equilibrios: preservar la intimidad ${ }^{24}$ y posibilitar el derecho a la información y la publicidad; garantizar un medio ambiente adecuado y permitir un desarrollo del deporte dependiente, en gran medida, del entorno natural y favorecedor de su sostenibilidad antes que provocador de la agresión.

Así pues, la especialización tendrá que llegar después de la formación generalista en Derecho deportivo para que se pueda responder con autoridad a conflictos constitucionales en la confrontación de bienes jurídicos y derechos fundamentales; como también al especialista le tocará aportar respuestas en que ordenación territorial, urbanismo, medio ambiente y deporte se den la mano; o para alcanzar una tributación progresiva y justa con el estímulo para mantener domiciliado fiscalmente al deportista de alto nivel.

Son ya muchas las iniciativas académicas que son respuesta a esta inquietud por la formación en Derecho del Deporte, en el marco internacional, destaca el Centro Internacional del Derecho Deportivo (ASSER International Sports Law Centre) que mediante su Instituto aúna a diferentes Universidades en la investi-

23 Así Circular número 1171/2008, de 24 de noviembre de 2008, firmada por el Secretario General de la Féderation Internationale de Football Association (FIFA) sobre requisitos mínimos para contratos estándar de jugadores de fútbol profesional.

24 De reconocimiento en la Ley y confirmación en todos los Estatutos de las distintas Universidades. gación y desarrollo del derecho del deporte a través de sus programas de investigación sobre derecho deportivo europeo e internacional desde una perspectiva interdisciplinaria. A juicio de esta institución el Derecho Deportivo manifiesta una rápida expansión y ha desarrollado un espacio en el debate jurídico y de de la investigación. Es a la vez un ámbito de actividad profesional importante y creciente de análisis académico, donde las reglas de la comunidad deportiva internacional y nacional forman la columna vertebral del derecho deportivo. El Derecho Deportivo es esencialmente un área de aplicación donde la ley se funde con el deporte en un contexto nuevo en el que la norma opera en una nueva realidad donde se transforma y adquiere perfiles actuales todo el espectro de la erudición jurídica tradicional ${ }^{25}$.

El rumbo marcado por en el panorama internacional, especialmente el compromiso de las universidades estadounidenses con el fomento del deporte, ha definido el camino de las Universidades españolas, que sensibles con esa necesidad han incorporado a los estudios de Derecho la materia deportiva. El tratamiento en sede universitaria legitima la formación como superior, científica y de rigor, lo que se traduce en una intensa y creciente producción de la labor investigadora con la aparición de numerosas publicaciones de alto valor científico e impacto ${ }^{26}$. Con ello se consiguen herramientas de estudio, investigación que da solvencia a la formación y soporte para el desarrollo con la necesaria transferencia de resultados.

\section{La experiencia de la UCAM receptora e impulsora del Derecho deportivo}

La experiencia de esta Universidad no es única ni es excluyente pero sí es un referente para comprobar el impulso necesario de este Derecho. Con base en la motivación ya expuesta, se aprovecha la nueva programación de la titulación de Derecho para incluir esta asignatura de Derecho deportivo con carácter optativo.

25 El ASSER International Sports Law Centre enmarca la participación de los siguientes Centros Universitarios de Derecho Deportivo: Yale Law School: Sport and the Law Course (USA), Hellenic Centre for Research on Sports Law (HCRSL) (Grecia), Sport and Law (Rusia), The German and International Sports Law Research Unit (Alemania), Sports Law Center of Shandong University (China), The University of Western Ontario: Course Law \& Sport (Canada), Centre de Droit et d'Economie du Sport (CDES/ Université de Limoges) (Francia), University of London-King's College (Inglaterra). Cfr. www.asser.nl

26 Desde la UCAM se publica la Revista de Ciencias de la Actividad Física y del Deporte Cultura Ciencia y Deporte CCD, publicación periódica cuatrimestral que nació el año 2003. 
Esta Universidad apuesta decididamente por el deporte y su tratamiento, con iniciativas académicas importantes: la titulación misma de CAFD, otras titulaciones de desarrollo en postgrado como el Máster de Dirección y Gestión de Entidades Deportivas, el Máster de Traumatología del Deporte, con sede científica en la Cátedra de Traumatología del Deporte; y todo ello desde un fomento de la actividad física con un Servicio de Deportes de reconocido prestigio por el éxito en resultados y un plan de acción social que incluye el incentivo laboral del ejercicio físico facilitando su realización con una ayuda económica para la matrícula en el centro deportivo UCAM Sport Center.

Tiene la Universidad como institución una presencia en el mundo deportivo al ser contemplada reglamentariamente su participación en la Comisión de Disciplina dependiente de la Comunidad Autónoma. Como también, y fuera del estricto marco académico, despliega la Universidad una importante labor de patrocinio que prefiere fijar en el deporte antes que en otras manifestaciones culturales o sociales. Seguramente una identidad católica exigente con la preservación y propagación de unos valores tendentes a la exaltación de la dignidad de la persona, del desarrollo de la personalidad, de la dimensión social del individuo, todos ellos valores que el deporte fortalece, es una razón nuclear para esa apuesta académica decidida a favor del deporte.

Además, la titularidad privada de esta Institución es otro argumento de actualidad para creer en el fomento del deporte y, en concreto, en el desarrollo de su Derecho ordenador, apostando por la despublicización para confiar en la iniciativa privada. Por tanto, identidad católica y titularidad privada se pueden reconocer presupuestos legitimadores y motivadores para ese impulso del deporte y su inclusión decidida en la oferta académica. Precisamente esa titularidad privada tampoco se plantea con cualquier manifestación sino desde la búsqueda del bien e interés público que caracteriza a toda persona jurídica de carácter fundacional.

Es la Universidad, por definición, un centro de estudio e investigación con vocación de proyección internacional; y ese carácter fundamental y definidor hoy se pretende impulsar con la exigencia de adaptación a un espacio supranacional y con la facilitación de una movilidad de la comunidad universitaria, alumnos y profesores.

Y en este panorama de revitalización de una visión globalizada de los compromisos y retos académicos es donde la UCAM ha recogido el testigo con plena responsabilidad, sabiéndose llamada por doble razón a una internacionalización que la identidad católica plantea también.
Pues bien, en este orden de cosas, el fomento de disciplinas de implantación general y de contenidos comunes, regímenes unitarios o llamados a concordarse e integrarse, son particularmente necesarios, tal como ocurre con el Derecho deportivo.

Por demás, abundando en la definición misma de la Universidad como servicio público, se puede saber llamada a ofrecer unos estudios que resultan particularmente atractivos y útiles a las personas provenientes del deporte, sobre todo los profesionales que, según se ha puesto de manifiesto, merecen una tutela académica para completar y asegurar su futuro profesional en la segunda actividad que el solo deporte nos les puede ofrecer. Cuanto más esta noble tarea se puede facilitar en una Institución como la UCAM que, por razón de incluir en su oferta de títulos Ciencias de la actividad física y del deporte, puede sentirse especialmente llamada a cubrir esa demanda de deportistas profesionales formados en esa titulación para ofrecerles la formación jurídica como segunda carrera. Doble titulación muy útil para una proyección en el tiempo de los estudiantes. Facilitándose la impartición por el provecho de sinergias y empleo óptimo de recursos humanos y materiales.

\section{Contenidos necesarios para la programación académica}

La formación jurídica de los extremos relevantes del deporte pasa por entender su interdisciplinariedad, partiendo, según se ha dejado ya apuntado por una relevancia de los aspectos civilistas y un marco de reconocimiento constitucional. Según aquéllos se podrá abordar, desde el Derecho general y común, el contenido principal; $y$, desde éste, se abre el tema a sus aspectos más ius publicistas, desde que es el Estado el llamado al fomento y garantía del deporte y, por ende, a la asunción de la titularidad de infraestructuras deportivas y de la organización de eventos.

El referente constitucional, desde el Derecho Público, exige profundizar en un Estado complejo que se ha de conocer en su reparto competencial; como también, más allá de una actividad de los Poderes Públicos, hay que confiar en la iniciativa privada para impulsar el deporte, según un régimen de libertad de empresa que la propia Constitución proclama.

Esta consideración necesaria del deporte en el mercado explicará también sus aspectos negociales y la necesaria rentabilidad a través de una masificación y profesionalización.

El deporte está desarrollando un amplio corpus normativo, doctrinal y jurisprudencial porque, según se 
tiene apuntado, no es nueva la actividad pero sí su configuración actual que expresa un llamamiento universal para que toda la población haga deporte y una diversidad de disciplinas (en gran medida nacidas desde la inquietud por la espectacularidad) y multiplicación de eventos (precisamente ofertados a partir de una mayor demanda de un público interesado por un espectáculo cuyo interés está avivado por aquella espectacularidad) que exigen regulación nueva y especializada.

El deporte tiene que ser presentado de un modo atractivo para invitar a toda la ciudadanía a su práctica, como también su viabilidad, la de las instalaciones sobre todo, pasa por interesar a la población en su seguimiento. A partir de este calado social es más fácil enseñar el Derecho relativo a una realidad tan cercana, tan próxima a la sociedad en general y tan interesante, propia y atractiva para la población estudiantil, joven en general; $y$, desde luego, más necesario profundizar en un Derecho relativo a un realidad tan cercana y tan relevante.

El espectáculo del deporte tiene que renovarse y mejorarse continuamente y, en esta dinámica, se manifiestan realidades con dimensión jurídica: profesionalización del deporte (y un estatuto jurídico de deportistas profesionales), deportes de riesgo (y la configuración de la empresa que ha de dotar de medios, junto con la consideración de otros extremos como la regulación de los requisitos de acceso o participación), espectáculo de masas (con una necesaria ordenación del control de esa masificación, de su difusión mediática).

Efectivamente se ha exigido una profesionalización para la consecución de retos, objetivos y calidad de ejecución, por lo que la dedicación del deportista en exclusiva a su entrenamiento y superación se hace realidad pero, lógicamente, a costa de un armamento jurídico ordenador de muchos factores: relaciones laborales especiales, empresa contratante (allí una regulación del estatuto del deportista profesional; aquí la constitución de sociedades deportivas de capital); incluso la prevención de una tentativa de dopaje, como medio de consecución de esos más altos objetivos, que ha supuesto una reciente reforma del código penal para castigar como tipo especial el tráfico de drogas entre deportistas (reforma del CP del 2010). Este aspecto siniestro del dopaje también ha merecido un tratamiento especial con una ley dedicada a la prevención y erradicación del dopaje en el deporte.

Ese espectáculo de masas ha traído novedades legislativas de necesaria referencia, como la relativa a la prevención de la violencia en el deporte. Pero la masificación es un argumento de presión que impulsa nuevas disciplinas o el mantenimiento de las más tra- dicionales pero con un plus de espectacularidad, pudiendo encontrar en esta constatación una explicación del desarrollo de los llamados deportes de riesgo ${ }^{27}$.

Efectivamente, aunque se parte de la consideración del deporte como una realidad impregnada siempre de riesgo, al propio, normal e inherente se suma un plus de peligrosidad que ciertas disciplinas aportan. Entonces se tiene que hablar, necesariamente, de una regulación que venga a evitar una mayor siniestralidad (como la regulación limitativa de una actividad de moto acuática en el espacio y en la habilitación).

La profesionalización y la masificación (sabiendo que ésta exige aquella y aquella provoca ésta, sobre todo porque el deporte se mejora en calidad y se hace espectáculo y fenómeno de interés y encuentro social) también da una particular complejidad a la empresa deportiva que, como fuente de riqueza, capital y empleo, merece un tratamiento jurídico que atienda ese volumen de negocio que mueve la organización.

Esta proliferación del deporte necesita de unas infraestructuras propias (polideportivos, gimnasios, campos de fútbol, circuitos de velocidad...) que, por su tamaño, ya condicionan la zonificación u ordenación del territorio de las ciudades. Como también los espacios físicos deportivos mixtos o compatibles con otros usos merecen un tratamiento que condiciona el tráfico o circulación viaria (carril bici); incluso deben restringirse cuando su impacto ambiental sea negativo (ski, motocross).

Recapitulando, se trata de conseguir una formación jurídica que aborde la materia desde los fundamentos y visualice una realidad tan compleja que puede sugerir una especialización ulterior ${ }^{28}$. Como también se ha de procurar acontar unos contenidos jurídicamente relevantes por razón de lo que el Derecho del Deporte supone para la ordenación de su objeto y por lo que implica en la regulación de otras materias (así se puede tratar la materia relativa a la justicia deportiva como una temática ejemplar para promover la solución extrajudicial de conflictos, como también se puede abordar la materia

27 "La postmodernidad... impulsa la aparición continua de nuevos deportes: de deslizamiento, de naturaleza, de aventura, de riesgo controlado, etc. Y crea nuevas modalidades deportivas, como el triatlón, con la combinación de prácticas tradicionales ya consolidadas". Mosquera González, Mª J., Sánchez Pato, A., Romero Zaragoza, M. y Cebrián Sánchez, Y. (2010). La perspectiva de género en la cultura de la No-violencia. Pautas educativas, Revista de Ciencias de la Actividad Física y del Deporte Cultura Ciencia y Deporte CCD, 14, 120

28 Aquí es interesante el tratamiento que han dado a esta materia desde la Universidad alemana de Bayreuth, Departamento de Derecho Civil, Mercantil y Económico y el de Derecho comparado y Derecho del deporte (Dept of Civil Law, Commercial and Economic Law, Comparative Law and Sports Law), donde responden en su programa desde diversos enfoques a la pregunta "Qué es exactamente el Derecho deportivo" (What exactly is sports law? ). Prof. Peter W. Heermann. 
relativa a la incidencia del deporte en la actividad económica o en la conformación de las ciudades, en tanto la creación de equipamientos deportivos es un elemento importante en el planeamiento urbanístico.

Por tanto, según esa localización de contenidos relevantes, para conformar un programa de asignatura se debe seguir una sistemática que ordene el temario desde un marco constitucional, que sirve para proclamar la actividad como de alto rango y de garantía estatal, la competencia pública en la tarea legislativa, administrativa y judicial; y otros referentes constitucionales para entender el marco supranacional comunitario en el que estamos integrados y que explica una libre circulación y unificación de régimen legal; así como para integrar y desarrollar la actividad deportiva en el entorno de un libre mercado y en un medio ambiente preservado.

También se trataría la clave jurídica según la materia civil que da la teoría fundamental de fuentes (que termina de completar la jerarquía que encabeza la Constitución), de contratos (que luego explica una contratación laboral especial y otra contratación mercantil de relevancia y práctica para el deporte como la esponsorización y el contrato de sociedad); y de responsabilidad civil (fundamental para solucionar un tema capital cual es, como en toda actividad de riesgo, la cobertura en la siniestralidad ${ }^{29}$ ).

El contenido anterior se completa con el necesario tratamiento de Derecho Público para profundizar en la labor de la Administración para el fomento del deporte, con el conocimiento que se precisa desde una división territorial que separa la autonómica de la central y la municipal; aunque esa labor de fomento, según se insiste, debe quedar, antes que en la titularidad y gestión pública, en el escenario normativo para incentivar la empresa privada. Así se siguen fijando contenidos fundamentales en el Derecho privado especial, mercantil, relativo a sociedades deportivas y laboral, relativo a relaciones laborales especiales en el ámbito del deporte.

No es arbitrario sino riguroso hacer, en fin, una fijación de extremos jurídicamente relevantes en dos sectores del Ordenamiento: el civil, por responder, entre otros temas, a la solución del debate de la responsabilidad ante la siniestralidad consecuencia de su riesgo inherente; y el internacional, por servir a la ordenación de un Derecho supranacional. Insistir en el orden penal es mantener una visión negativa del deporte y criminalizar sus conductas, aunque su estudio

29 El estudio de la materia relativa a la Responsabilidad civil ya nos ha ocupado en trabajos anteriores como el publicado bajo el título Derecho y Deporte. Particular referencia a los accidentes deportivos. Responsabilidad civil y riesgos en el deporte. De la Torre Olid, F. (2008). Revista de Aranzadi de Derecho del Deporte y Entretenimiento, 24, 31. se tenga que abordar desde que hay ciertamente tipos delictivos de especial fijación para el ámbito deportivo o de especial frecuencia en esta realidad. Apostar por un estudio principalmente administrativista es seguir confiando en la iniciativa pública como sustento del deporte cuando la apuesta para la fortaleza y viabilidad es la del mercado.

\section{Recapitulación y conclusiones}

\section{Recapitulación}

Desde la perspectiva de la enseñanza del Derecho, en el nuevo marco de la Educación Superior, el Derecho deportivo ha dejado entenderse como una materia de tratamiento especializado para pasar a considerarse una materia digna de tratamiento generalista; y, por tanto, desde estas líneas se aboga por su inclusión en los planes de estudio del Grado de Derecho, fundamentalmente dirigidos a esa formación generalista, cuanto más si responde, como es objetivo del Grado, al compromiso de empleabilidad o formación idónea para la inserción laboral.

Efectivamente, la conveniencia de formarse en este Derecho se hace más oportuna cuando se comprueba que trata de una realidad cercana al alumno, por lo que su interés está asegurado. Interés necesario para afrontar una realidad que es muy general en sus contenidos (interdisciplinares), en su proyección social (universal) y territorial (internacional, global). Un Derecho que forma en unas competencias muy necesarias para todo individuo $y$, en particular, para el jurista, ya que se impregnan unos valores que tienen que ver con la positiva sensibilidad medioambiental, con el necesario y competitivo trabajo en equipo, con la adaptación necesaria a nuevas realidades y culturas, con la igualdad de las personas, con la unidad del Ordenamiento. Un Derecho que sirve para tomar el pulso a la sociedad desde el hecho deportivo tan masivo, dinámico, complejo y, por ende, escuela y expresión de socialización, superación, compromiso ético. Se puede decir que estudiar el Derecho deportivo es fomentar el Deporte y posibilitarlo para afianzarlo y asegurarlo con su ordenación.

Esta formación generalista es basamento para afrontar una especialización que prepare en un Derecho emergente, como es el Derecho deportivo, ahora ya en su consideración dinámica para afrontar, desde su conformación y consolidación como general, el estudio de las soluciones jurídicas que han de venir para resolver los problemas en clave tributarista, mercantilista, etc. 
El Derecho deportivo como materia académica se ha de ofertar desde la Universidad, sede de rigor y excelencia; con particular reconocimiento a la iniciativa privada, consagrando el referente de la despublicización, según se ha insistido en este trabajo; y con expreso reconocimiento de la legitimidad para esta iniciativa u oferta académica en una Institución de la Iglesia, por los valores que se defienden y, más en particular, de la UCAM, en cuanto que se muestra una experiencia acorde a esta propuesta.

\section{Conclusiones}

$1^{\circ}$ El tratamiento jurídico como tarea fundamental para la garantía del hecho deportivo.

En lo relativo al tratamiento jurídico del deporte, se concluye en el sentido de poder entender que no es uno más sino el primordial, porque la normativización necesaria está fijada como elemento esencial o definidor del deporte y porque la garantía de su realización pasa por su proclamación constitucional (constitucionalización del deporte) y por dotarlo de (plena) eficacia jurídica. Incluso la sola consideración del hecho deportivo, si es visto en sus manifestaciones espontáneas, como actividad social y de riesgo que es, tiene ya unos contenidos jurídicamente relevantes que precisan ser abordados en cualquier caso.

$2^{\circ}$ La programación del Grado de Derecho como momento oportuno para la inclusión del Derecho del deporte.

Entre las conclusiones de este trabajo también puede quedar esa oportunidad de introducir el Derecho del deporte en la programación del Grado de Derecho, razonando esta propuesta en cuanto que esta materia ha dejado de entenderse como una vía solo de especialización, que también lo sigue siendo, al configurarse con un carácter general, en tanto heredero de toda una tradición y principios propios del sistema jurídico y por razón de su implantación universal y vocación de consolidación con uniformidad de contenidos, sirviendo entonces a la formación generalista y útil, además, para ejercitar la habilidad de la interdisciplinariedad a favor de la unidad del Ordenamiento Jurídico. De igual modo, al ser una respuesta jurídica para una realidad cambiante, permite comprender la agilidad del Derecho para dar respuesta a las cuestiones que surgen ex novo y que, ya en una formación de especialización, sugerirán los complementos formativos e itinerarios de expertos.

$3^{\circ}$ El Derecho del deporte, una materia idónea para adquirir competencias fundamentales.

Las competencias que se adquieren con el estudio del derecho deportivo son necesarias en la formación superior, aportando su virtud tanto como materia deportiva como materia jurídica, al suponer la materia deportiva en todos sus acercamientos una comprensión de la conveniencia del trabajo en equipo y de la necesaria preservación de valores como la igualdad, la sociabilidad, el compromiso ético y la protección medio ambiental; y, más en particular, en la formación jurídica, con ocasión del estudio del derecho del deporte, se garantiza una cualificación en la visión interdisciplinar de la realidad y en la necesaria unidad del Ordenamiento Jurídico, así como la exigencia de dar respuestas a una realidad cambiante y compleja.

$4^{\circ}$ Una formación general necesaria para una especialización ulterior.

La consideración del derecho del deporte como general permite su encuadramiento normal en la programación del Grado, de gran interés precisamente para tener la base y conocimientos necesarios que permitan afrontar el estudio de especialización que el derecho deportivo requiere para el profesional que se va a proyectar y desarrollar según en qué sectores: fiscal, mercantil, laboral, civil, administrativo.

$5^{\circ}$ La proclamación de la relevancia jurídica de la materia encadenada con la fijación de unos contenidos necesarios.

Así es cuanto al ocupar la realidad material se proyecta con relevancia jurídica en aspectos jurídicamente relevantes cuya naturaleza es tan variada como sectores del Derecho se reconocen, en cuanto el deportista profesional plantea perfiles especiales como sujeto pasivo de la Administración Tributaria, en cuanto la Administración al garantizar y promocionar el deporte se convierte en titular de numerosas infraestructuras o ha de dedicar un departamento a esa labor garantista; como también la consideración del deporte en el mercado nos lleva a hablar de un negocio cuya titularidad o explotación interesa a la iniciativa privada; como también la profesionalización del deportista nos exige acuñar nuevos tipos de contratos de trabajo especiales por su temporalidad, horarios, cláusulas de atípicas de explotación de imagen o esponsorización, etc.

$6^{\circ}$ La problemática práctica muestra la utilidad del Derecho para pacificar o solucionar el conflicto que se desate en el deporte.

La intensa actividad que representa el deporte arroja importantes cifras de conflictividad o debate que abocan a un estudio de causas para la prevención o solución. Se tiene que saber de su debate, conflicto o contienda judicial para detectar las zonas de enfrentamiento más frecuentes que precisan la mayor eficacia 
jurídica para su solución o pacificación. Destacando en este punto de modo sobresaliente la solución extrajudicial que de la mano de la autonomía de la disciplina deportiva se consigue.

$7^{\circ}$ El deporte marca tendencia para un desarrollo del Derecho acorde a los tiempos que vive la sociedad y a sus intereses.

La afluencia masiva de personas en el ámbito deportivo, la intensidad con que se vive la experiencia deportiva, son argumentos que explican por qué en el deporte y a propósito de su ordenación jurídica se han ido configurando respuestas que han sido referentes para una evolución del Derecho. Así se pueden poner ejemplos concretos y reconocer la eficacia de las soluciones extrajudiciales de conflictos que pretenden ser hoy día medidas a desarrollar y generalizar. Como también se puede hablar de una flexibilidad en la contratación o de un debate de la responsabilidad donde se comprende bien la cuasiobjetivación de la responsabilidad y la necesidad de asumir riesgos. Es además el ámbito deportivo el que muestra la vanguardia de algunas miserias de la sociedad como la violencia o el dopaje y ello porque, a pesar de las bondades de su realidad, al hacer concurrir una masa social tan relevante ya es sede para un observatorio de la dinámica social en sus patologías. Esa misma vanguardia o expresión de vitalidad social es exigente con soluciones nuevas o de referencia para otras realidades sociales como en conflictos comunes entre intimidad y libertad de expresión.

$8^{\circ}$ La ordenación jurídica del deporte determina cómo se va a configurar y desarrollar el fenómeno deportivo.

Reflexionar sobre el Derecho del deporte permite concluir que la regulación jurídica del fenómeno deportivo es determinante de su viabilidad y que, según se regule jurídicamente, así se concibe y se desenvuelve ese hecho deportivo.

Se asiste a la liberalización y socialización del deporte por lo que, en clave jurídica, se crea un escenario en el que el deporte es una oportunidad de mercado, como también se ofrece y se fomenta para toda la población, abstracción hecha de la consideración patrimonial de la persona. Así se está concibiendo como una manifestación de la iniciativa emprendedora, incluso desde la sede académica y empezando por la oferta de contenidos formativos, en grados, postgrados, congresos; para continuar con toda manifestación deportiva que también la Universidad contempla necesariamente. Y también se está concibiendo como una actividad de rango social por la consideración del interés general, el bien jurídico que protege de formación en valores y para el desenvolvimiento de la personalidad.

\section{BIBLIOGRAFÍA}

Castro Conte, M. (2009). Desarrollo legal y situación de la mujer en el deporte, Revista Aranzadi de Derecho del Deporte y Entretenimiento, 26, pp. 95-112.

De la Torre Olid, F. (2008). Revista de Aranzadi de Derecho del Deporte y Entretenimiento, 24, pp. 351-369.

Fernández Rodríguez, T. R. (2009). Revista Aranzadi de Derecho del Deporte y Entretenimiento, 27, pp. 17-28.

Ian S. Blackshaw y Robert C. R. Siekmann (2005). Sports Image Rights in Europe. T.M.C Asser Press La Haya.

Molina Navarrete, C. (2009). Revista Aranzadi de Derecho del Deporte y Entretenimiento, 26, pp. 43-64.

Monrov Antón, A.J. (2008). Revista Aranzadi de Derecho del Deporte y Entretenimiento, 25, pp. 147-148.

Mosquera González, Mª J., Sánchez Pato, A., Romero Zaragoza, M. y Cebrián Sánchez, Y. (2010). La perspectiva de género en la cultura de la No-violencia. Pautas educativas, Revista de Ciencias de la Actividad Física y del Deporte Cultura Ciencia y Deporte CCD, 14, pp. 120-127.

Palomar Olmeda, A. (2009). Un intento de acotar el interés general deportivo: pautas para su eventual revisión y como consecuencia del papel de las Administraciones públicas en el deporte. Revista de Derecho del Deporte y Entretenimiento, 27, pp. 185-225.

Palomar Olmeda, A. (2009). La modernización de la gestión pública del deporte. Revista Aranzadi de Derecho del Deporte y Entretenimiento, 25, pp. 93-95.
Sánchez Rodríguez, F y Punzón Moraleda, J. (2009). La inclusión del “derecho deportivo" en los nuevos títulos de grado de la física y del deporte. Revista Aranzadi de Derecho del Deporte y Entretenimiento, 25, pp. 17-30.

\section{Apéndice Legislativo:}

Ley Orgánica de Universidades, Ley Orgánica 6/2001, de 21 de diciembre, de Universidades, Boletín Oficial del Estado, 307, de 24 de diciembre de 2001, pp. 49400-49425.

Ley 10/1990, de 15 de octubre del Deporte, de 15 de octubre del Deporte, Boletín Oficial del Estado, 249, de 17 de octubre de 1990, pp. 30397-30411.

Ley 19/2007, de 22 de marzo, para la Igualdad efectiva de Hombres y Mujeres contra la violencia, el racismo y la xenofobia en el deporte, Boletín Oficial del Estado, 71, de 23 de marzo de 2007, pp. 1261112645.

Real Decreto 1393/2007, de 29 de octubre, por el que se establece la ordenación de las enseñanzas universitarias oficiales, Boletín Oficial del Estado, 260, de 30 de octubre de 2007, pp. 44037-44048, modificado parcialmente por el RD 861/2010 de 2 de julio, Boletín Oficial del Estado, 161, de 4 de julio de 2010, pp. 58454-58468.

Circular número 1171/2008, de 24 de noviembre de 2008, firmada por el Secretario General de la Féderation Internationale de Football Association (FIFA) sobre requisitos mínimos para contratos estándar de jugadores de fútbol profesional. 